\title{
Risk Analysis and Management of Coastal Zone, Estuary and Offshore Ecological Environment
}

\author{
Liqiang \\ Saifeite Engineering Technology Group Co. Ltd
}

Floor 7, Building 1, Minghui International, 39 Shiling Road, Laoshan District, Qingdao City, Shandong Province

\author{
海岸芇、河口等芹海生态环境

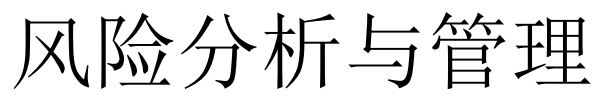 \\ 李强 \\ 赛飞特工程技术集团有限公司, 山东省青岛市崂山区石岭路 39 号名汇国际 1 号楼 7 层
}

\begin{abstract}
China is a marine country,there are convenient sea passages and abundant marine resources. Make the coastal areas become densely populated, urban concentrated, and industrially dense, Gathering heavy pollution industries such as nuclear power, electronics, medicine, heavy chemicals and metallurgy. The amount of sewage discharged from urban domestic sewage, industrial and agricultural wastewater and offshore aquaculture has increased dramatically to the oceans and estuaries. COD, total phosphorus, suspended solids and ammonia nitrogen exceed the standard seriously. The ecological environment and bio-community quality of coastal coasts, estuaries and offshore wetlands are seriously degraded, lead to degradation of many marine ecosystems. The article analyzes the status quo of environmental protection in coastal industrial zones and the future trend of environmental protection, which leads to the main influencing factors of the great changes in coastal, estuary and offshore ecological environment. discharge of industrial wastewater, domestic wastewater and other large amount of wastewater in industrial areas has an impact on the water quality of the sea area. Impacts on the composition and structure of marine ecosystems, using regional risk assessment technology and methods, the environmental risk and grading of coastal industrial zones are determined through source strength analysis, environmental consequence analysis, risk characterization, risk assessment and risk management. The present situation and future development trend of marine environmental monitoring and risk management are analyzed and discussed in detail. Suggestions on optimizing environmental protection measures in coastal
\end{abstract}

industrial parks, integrating basic information such as risk sources and marine ecological monitoring, and strengthening risk management of offshore marine ecological environment are put forward.

Keywords-- offshore ecological environment; industrial zones; risk management

摘要: 中国是一个海洋国家, 有着便利的海上 通道和丰富的海洋资源。使得沿海地区成为人口密 集, 城市集中, 工业密集的地方, 聚集着核电、电 子、医药、重化工, 冶金等重污染产业。城市生活 污水、工农业废水和近海养殖业产生的污水向海洋、 河口排放的数量急剧增加, $\mathrm{COD}$ 、总磷、悬浮物和 氨氮严重超标。沿海海岸、河口与近海湿地的生态 环境和生物群落质量均严重下降, 导致许多海洋生 态系统的退化。文章从沿海工业区环境保护现状分 析和未来的环境保护趋势, 引出沿海海岸、河口与 近海生态环境发生巨大变化的主要影响因素, 论证 工业区的工业废水、生活污水等大量污水的排放对 海域水质的影响, 对海洋生态系统的组成和结构造 成的影响, 进而论述沿海海岸、河口与近海生态环 境的风险识别, 利用区域风险评价技术方法, 通过 源强分析、环境后果分析、风险表征和风险评价及 风险管理等评价过程, 确定沿海工业区环境风险和 等级划分。详细分析和探讨海洋环境监测与风险管 控能力的现状和未来发展趋向, 提出了优化沿海工 业园区环境保护措施, 整合汇集风险源、海洋生态 监测等基础信息, 加强近海海洋生态环境风险管理 的建议。

关键词一近海生态环境, 工业区, 风险管理

\section{I. 概述}

我国的海洋资源居世界第四位，拥有 1.8 万千米的海岸线和约 300 万平方千米的 海洋国土面积, 有便利的海上通道和丰富的 
海洋资源。海岸带交通便利、人口众多、经 济发展迅速。在中国大陆 11 个沿海省、直 辖市和自治区的面积只占全国陆地面积 $13 \%$ ，却集中全国 50\%以上的大城市、 $40 \%$ 的中小城市、 $42 \%$ 的人口和 $60 \%$ 以上的国内 生产总值, 形成环渤海地区、长江三角洲、 闽南三角区、珠江三角洲四个经济发达地区， 同时成为核电、电子、医药、重化工和冶金 等工业密集区域。随着沿海地区经济社会快 速发展, 沿海带、河口与近海海洋环境、水 环境和生态环境问题日益凸显, 已影响到沿 海带和河口带地区经济崛起的国家战略实 施。
II. 沿海带、河口与近海污染现状分析

2.1 无序的填海造地活动, 形成大量人 工海岸线

我国大陆人工海岸线的长度由 20 世纪 40 年代初期的 $0.33 \times 104 \mathrm{~km}$ 上升至 2014 年的 $1.32 \times 104 \mathrm{~km}$, 比例由 $17.9 \%$ 上升到 $71.7 \%$, 向海扩张趋势的海岸超过 $71.7 \%$; 自然海岸 线的长度由 20 世纪 40 年代初期的 $1.48 \times 104 \mathrm{~km}$ 下降至 2014 年的 $0.65 \times 104 \mathrm{~km}$, 比例由 $80.4 \%$ 下降为 $35.3 \%$ (全国自然海岸 保有率红线 2020 年前不低于 35\%), 接近国 家最低自然海岸线红线。自然岸线长度的锐 减导致海滨等重要生态系统损失严重。海洋 生态系统呈现亚健康状况。海洋生态系统健 康状况见表 1:

表 12017 年典型海洋生态系统健康状况表

\begin{tabular}{|c|c|c|c|c|}
\hline $\begin{array}{l}\text { 生态系 } \\
\text { 统类型 }\end{array}$ & $\begin{array}{l}\text { 生态监控区 } \\
\text { 名称 }\end{array}$ & $\begin{array}{l}\text { 监控区 } \\
\text { 面积 }\end{array}$ & $\begin{array}{c}\text { 健康状 } \\
\text { 况 }\end{array}$ & 影响因素分析 \\
\hline \multirow{5}{*}{ 河口 } & 双台子河口 & 3000 & 亚健康 & $\begin{array}{c}\text { 海水呈富营养化, 浮游植物密度过低, 浮游动物生物量过 } \\
\text { 低 }\end{array}$ \\
\hline & $\begin{array}{c}\text { 㴒河口-北戴 } \\
\text { 河 }\end{array}$ & 900 & 亚健康 & 浮游植物密度过低, 底栖动物密度和生物量过低 \\
\hline & 黄河口 & 2600 & 亚健康 & $\begin{array}{c}\text { 部分生物内铬、铅残留水平较高, 浮游动物生物量过低, } \\
\text { 鱼卵仔鱼密度过低 }\end{array}$ \\
\hline & 长江口 & 13668 & 亚健康 & $\begin{array}{c}\text { 海水呈富营养化, 监测到低氧区, 浮游植物、浮游动物密 } \\
\text { 度过低, 底栖动物密度过高, 生物量过低。 }\end{array}$ \\
\hline & 珠江口 & 3980 & 亚健康 & 海水呈富营养化, 浮游植物密度过高, 底栖动物密度过低。 \\
\hline \multirow{7}{*}{ 海湾 } & 锦州湾 & 650 & 不健康 & $\begin{array}{c}\text { 海水受石油类污染, 浮游植物密度过高, 浮游动物密度过 } \\
\text { 低, 底栖动物密度和生物量过高。 }\end{array}$ \\
\hline & 渤海湾 & 3000 & 亚健康 & $\begin{array}{c}\text { 浮游植物密度过高, 浮游动物生物量过低, 鱼卵仔鱼密度 } \\
\text { 过低, 底栖动物密度和生物量过高。 }\end{array}$ \\
\hline & 莱州湾 & 3770 & 亚健康 & $\begin{aligned} \text { 浮游植物密度过高, 浮游动物生物量过低, 底栖动物密度 } \\
\text { 和生物量过高。 }\end{aligned}$ \\
\hline & 杭州湾 & 5000 & 不健康 & $\begin{array}{c}\text { 海水呈富营养化, 浮游植物密度过高, 浮游动物密度过低、 } \\
\text { 生物量过高、底栖动物密度过低、生物量过高 }\end{array}$ \\
\hline & 乐清河 & 464 & 亚健康 & $\begin{array}{c}\text { 海水呈富营养化, 浮游动物生物量过低, 底栖动物密度过 } \\
\text { 高、生物量过低。 }\end{array}$ \\
\hline & 闽东沿岸 & 5063 & 亚健康 & $\begin{array}{c}\text { 海水呈富营养化, 浮游植物密度过高, 浮游动物密度和生 } \\
\text { 物量过高, 鱼卵仔高密度过低。 }\end{array}$ \\
\hline & 大亚湾 & 1200 & 亚健康 & $\begin{array}{c}\text { 部分生物体内镉、铅、砷残留水平较高, 浮游植物密度过 } \\
\text { 高, 浮游动物密度过低, 鱼卵仔鱼密度过低, 底栖动物密 } \\
\text { 度和生物量过低。 }\end{array}$ \\
\hline $\begin{array}{c}\text { 滩涂湿 } \\
\text { 地 }\end{array}$ & 苏北浅滩 & 15400 & 亚健康 & $\begin{array}{c}\text { 部分生物体内铅、砷残留水平较高, 浮游植物密度过高, } \\
\text { 鱼卵仔鱼密度过低, 底栖生物密度和生物量过高。 }\end{array}$ \\
\hline
\end{tabular}




\begin{tabular}{|c|c|c|c|c|}
\hline \multirow{3}{*}{ 珊瑚礁 } & 广西北海 & 120 & 健康 & 硬珊瑚补量维持较高水平。 \\
\hline & 海南东海岸 & 3750 & 亚健康 & 活珊瑚礁盖度处于近 10 年来的较低水平。 \\
\hline & 西沙珊瑚礁 & 400 & 亚健康 & 活珊瑚盖度较上年有所增加。 \\
\hline \multirow{2}{*}{ 红树林 } & 广西北海 & 120 & 健康 & $\begin{array}{c}\text { 红树林面积与群落类型基本稳定, 红树成树数量不变, 鸟 } \\
\text { 类种数持续增长。 }\end{array}$ \\
\hline & 北仑河口 & 150 & 健康 & $\begin{array}{c}\text { 红树林面积与群落类型基本稳定, 部分林区发生广州小斑 } \\
\text { 螟和袋蛾虫害, 受灾树种主要为白骨壤和桐花树。 }\end{array}$ \\
\hline \multirow[b]{2}{*}{ 海草床 } & 广西北海 & 120 & 亚健康 & 海草床仍处于退化状态。 \\
\hline & 海南东海岸 & 3750 & 健康 & $\begin{array}{c}\text { 与上年相比, 海南东海岸海草床生态系统的海草覆盖和密 } \\
\text { 度均有所下降。 }\end{array}$ \\
\hline
\end{tabular}

2.2 海岸蚀退和河口淤积加剧, 滨海土 地资源受损严重

根据国家海洋局 2017 年公报, 由于开 展海岸整治修复和人工护岸修建, 砂质海岸 侵蚀长度有所减少，但局部海岸侵蚀加重。 如海南琼海博鳌印象和三亚亚龙湾东侧监
测岸段侵蚀严重，2017 年侵蚀速度均超过 6.0 米/年。辽宁绥中岸段南江屯附近海岸最 大侵蚀距离 13.1 米/年; 粉砂淤泥质海岸江 苏振东河闸至射阳河口监测岸段侵蚀严重, 最大侵蚀距离 162 米/年。监测结果见表 2:

表 22017 年重点海岸段侵蚀监测结果表

\begin{tabular}{|c|c|c|c|c|c|}
\hline 重点岸段 & 侵蚀海岸类型 & $\begin{array}{c}\text { 监测海岸长度 } \\
\text { (公里) }\end{array}$ & $\begin{array}{c}\text { 侵蚀海岸长度 } \\
\text { (公里) }\end{array}$ & $\begin{array}{c}\text { 最大侵蚀速度 } \\
\text { (米/年) }\end{array}$ & $\begin{array}{c}\text { 平均侵蚀速度 } \\
\text { (米/年) }\end{array}$ \\
\hline 辽宁绥中 & 砂质 & 81.3 & 4.4 & 13.1 & 2.6 \\
\hline 辽宁盖州 & 砂质 & 22.1 & 1 & 8.3 & 1.6 \\
\hline 山东招远宅上村 & 砂质 & 1.5 & 1.2 & 3.6 & 1.1 \\
\hline 山东威海九龙湾 & 砂质 & 2.2 & 1.5 & 7 & 1.2 \\
\hline 江苏振东河闸至射阳河口 & 粉砂淤泥质 & 61.3 & 42 & 162 & 10.5 \\
\hline 上海崇明东滩南侧 & 粉砂淤泥质 & 48 & 2.7 & 20 & 1.6 \\
\hline 福建高罗海水浴场 & 砂质 & 0.2 & 0.2 & 0.7 & 0.4 \\
\hline 广东惠东红海湾 & 砂质 & 3.3 & 3.3 & 12.8 & 2.1 \\
\hline 广东茂名市电白县澳内海 & 砂质 & 0.4 & 0.3 & 5.1 & 3.8 \\
\hline 村 & 砂质 & 0.5 & 0.5 & 6.1 & 3.3 \\
\hline 广东雷州市龙德镇赤坎村 & 砂质 & 2.5 & 2.5 & 0.5 & 0.3 \\
\hline 广西涠洲岛石螺口至滴水 & 砂质 & 5.7 & 5.7 & 1.6 & 0.5 \\
\hline 村 & 砂质 & 1.9 & 1.7 & 18.4 & 6.1 \\
\hline 广西涠洲岛后脊塘至横岭 & 砂质 & 4.1 & 4.1 & 18.6 & 6.2 \\
\hline 海南琼海博鳌印象 & 砂质 & 2.6 & 2.6 & 18.2 & 2.5 \\
\hline 海南三亚亚龙湾东侧 & 海南昌江核电厂南侧 & & & & \\
\hline
\end{tabular}

2.3 沿海、河口排污对海岸水环境污染 严重

2.3.1 陆源污染物:

2017 年, 国家海洋局对全国 55 条入海 河流连续监测入海断面水质劣于第 $\mathrm{V}$ 类地
表水质标准的比例分别为 $44 \%$ 、42\%和 $36 \%$, 主要污染物要素为化学需氧量 (CODcr)、总 磷、氨氮和石油类。2017 年部分河流携带入 海的污染物量下表 3: 
表 32017 年部分河流携带入海的污染物量表（吨）

\begin{tabular}{|c|c|c|c|c|c|c|c|c|}
\hline 河流名称 & $\begin{array}{c}\text { 化学需氧量 } \\
\text { (CODcr) }\end{array}$ & $\begin{array}{l}\text { 氨氮（以 } \\
\text { 氨计） }\end{array}$ & $\begin{array}{l}\text { 硝酸盐氨 } \\
\text { (以氨计) }\end{array}$ & $\begin{array}{c}\text { 亚硝酸盐 } \\
\text { 氨 (以氨 } \\
\text { 计) }\end{array}$ & $\begin{array}{c}\text { 总磷（以磷 } \\
\text { 计） }\end{array}$ & 石油类 & 重金属 & 砷 \\
\hline 长江 & 6828604 & 42008 & 1359382 & 8612 & 153795 & 35589 & 4556 & 1950 \\
\hline 珠江 & 2672434 & 27373 & 479740 & 23169 & 43459 & 3104 & 2935 & 480 \\
\hline 鸭绿江 & 862200 & 29892 & 55942 & 1330 & 7303 & 134 & 528 & 53 \\
\hline 钱塘江 & 412602 & 9156 & 66053 & 3082 & 5060 & 848 & 521 & 74 \\
\hline 南流江 & 348695 & 4802 & 20594 & 1060 & 2573 & 697 & 73 & 8 \\
\hline 新洋河 & 301038 & 1537 & 2773 & 894 & 1115 & 518 & 92 & 11 \\
\hline 大辽河 & 209208 & 4434 & 44765 & 5295 & 3280 & 1159 & 289 & 49 \\
\hline 射洋河 & 207643 & 3475 & 3020 & 722 & 1338 & 721 & 96 & 15 \\
\hline 黄河 & 172558 & 2959 & 17764 & 361 & 1806 & 1748 & 304 & 13 \\
\hline 灌河 & 137953 & 4106 & 5207 & 304 & 2771 & 790 & 162 & 22 \\
\hline 函河 & 96045 & 2426 & 2747 & 82 & 879 & 76 & 29 & 4 \\
\hline 㴒河 & 95288 & 889 & 949 & 109 & 149 & 0 & 21 & 2 \\
\hline 大洋河 & 87437 & 2215 & 8542 & 314 & 455 & 3.5 & 84 & 5 \\
\hline 南渡河 & 83406 & 977 & 4003 & 56 & 762 & 198 & 75 & 8 \\
\hline 大风河 & 82740 & 700 & 2413 & 38 & 204 & 153 & 21 & 1 \\
\hline 东江 & 81413 & 5164 & 11520 & 951 & 2391 & 173 & 184 & 15 \\
\hline 黄沙港河 & 80679 & 592 & 1290 & 435 & 682 & 371 & 40 & 5 \\
\hline 榕江 & 80338 & 5229 & 4705 & 1022 & 830 & 370 & 53 & 2 \\
\hline 苏北灌溉总渠 & 69879 & 296 & 1146 & 292 & 310 & 160 & 23 & 4 \\
\hline 四卯酉河 & 67605 & 825 & 849 & 278 & 379 & 212 & 26 & 5 \\
\hline
\end{tabular}

\section{3 .2 海洋大气污染物}

国家海洋局在大连老虎滩、大连大黑石、 营口、盘锦、葫芦岛、秦皇岛、塘沽、东营、 蓬莱、青岛小麦岛、连云港、舟山、福建北 礵和珠海大万山等 15 个监测站开展海洋大 气气溶胶污染物含量监测, 监测结果见图 1。

\section{3 .3 海洋垃圾和微塑料}

国家海洋局在 49 个区域开展海洋垃圾 监测, 监测内容包括海面漂浮垃圾、海滩垃 圾和海底垃圾的种类、数量。海洋垃圾密度 较高的区域主要分布在旅游休闲娱乐区、农
渔业区、港口航运区计邻近海域，如图 2 所 示。

III．确定沿海工业区环境风险和等级划分 沿海区域工业区的工业废水、生活污水 等大量排放对近海域水质的影响, 致使海洋 生态系统的组成和结构发生变化，2017 年， 在对沿海海岸、河口与近海水质监测, 污染 海域主要分布在辽东湾、渤海湾、莱州湾、 江苏沿岸、长江口、杭州湾、浙江沿岸、珠 江口等近海、河口区域, 主要超标污染物为 无机氮、活性磷酸盐和石油类, 具体见表 4 : 


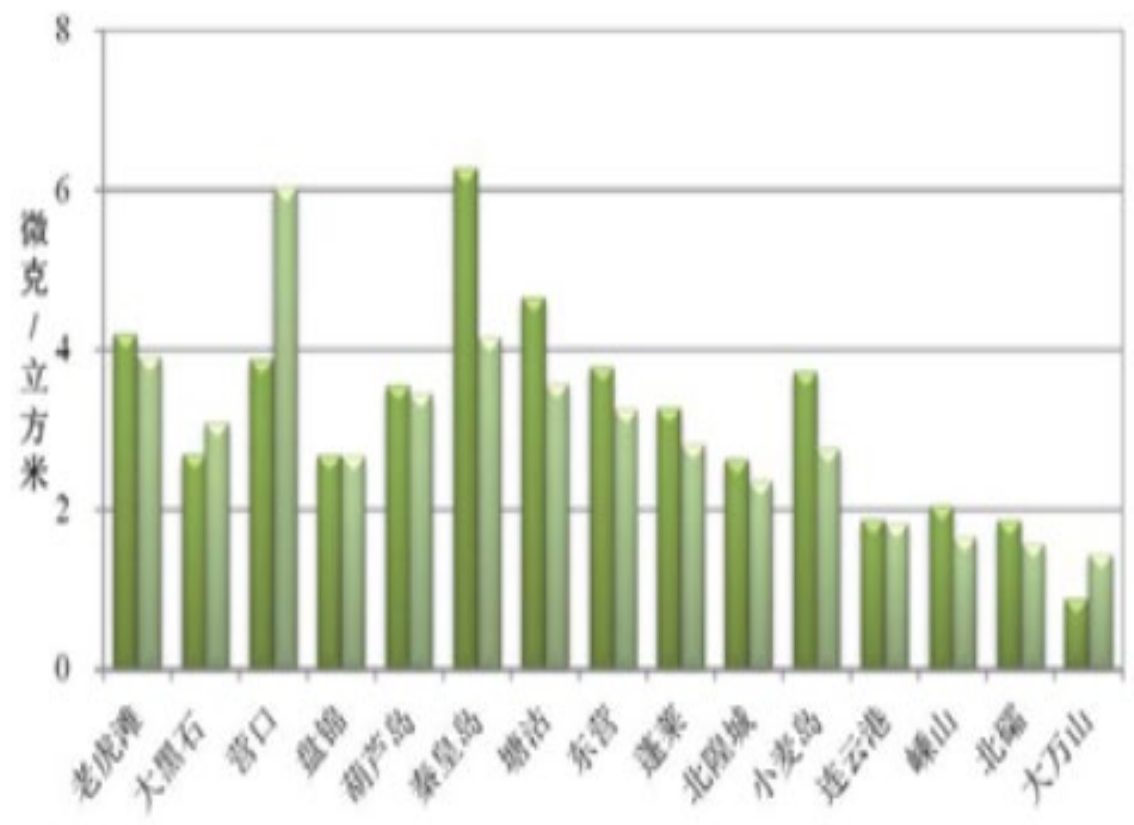

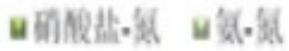

图 12017 年各监测站气溶胶中硝酸盐-氮和氨-氮的含量
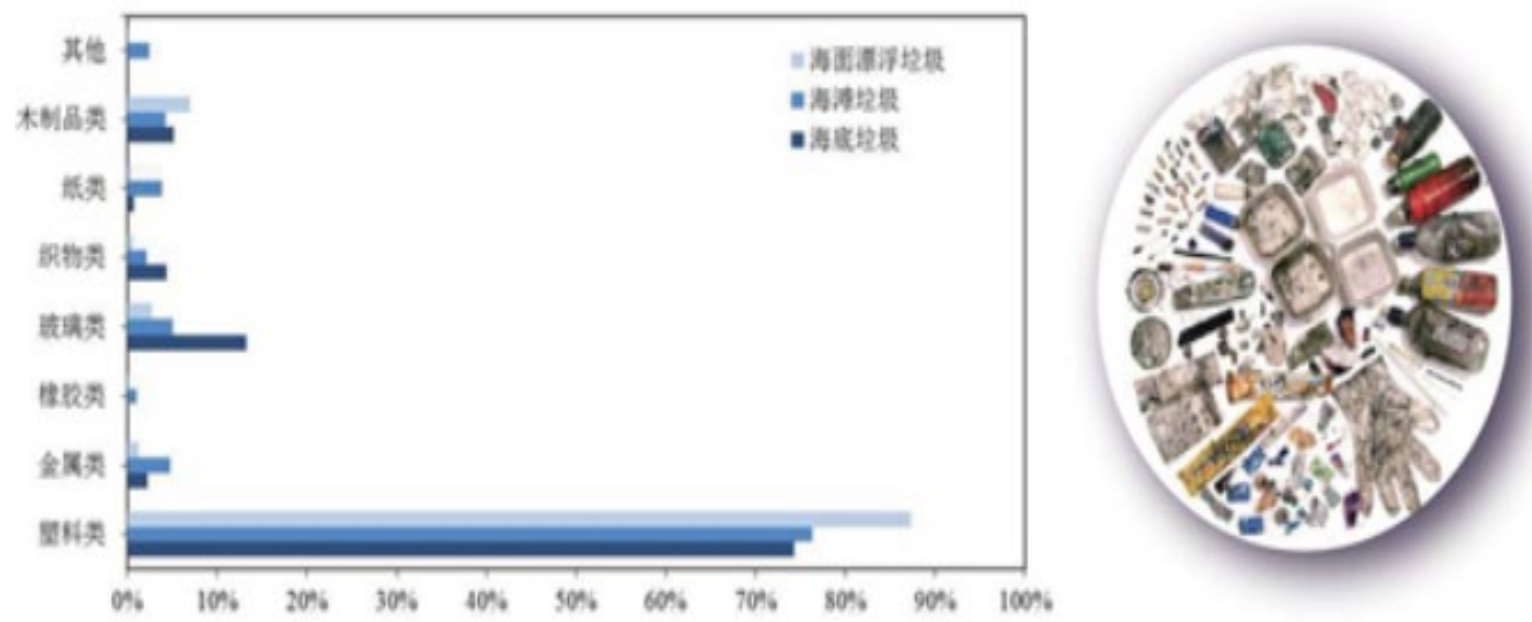

图 22017 年检测区海洋垃圾主要类型

表 42017 年管辖海域未达到第一类海水水质标准的各类海域面积表（平方公里）

\begin{tabular}{|c|c|c|c|c|c|c|}
\hline \multirow{2}{*}{ 海区 } & 季节 & $\begin{array}{c}\text { 第二类水质 } \\
\text { 海域面积 }\end{array}$ & $\begin{array}{c}\text { 第三类水质海 } \\
\text { 域面积 }\end{array}$ & $\begin{array}{c}\text { 第四类水质海 } \\
\text { 域面积 }\end{array}$ & $\begin{array}{c}\text { 劣于第四类水 } \\
\text { 质海域面积 }\end{array}$ & 合计 \\
\hline \multirow{2}{*}{ 渤海 } & 夏季 & 8940 & 3970 & 2120 & 3710 & 18740 \\
\cline { 2 - 7 } & 秋季 & 15710 & 8300 & 4780 & 3690 & 32480 \\
\hline \multirow{2}{*}{ 黄海 } & 夏季 & 17280 & 7090 & 2610 & 1240 & 28220 \\
\cline { 2 - 7 } & 秋季 & 20980 & 10980 & 9440 & 3840 & 45240 \\
\hline \multirow{2}{*}{ 东海 } & 夏季 & 17610 & 9260 & 11400 & 22210 & 60480 \\
\cline { 2 - 7 } & 秋季 & 23380 & 10260 & 11850 & 34510 & 80000 \\
\hline 南海 & 夏季 & 6000 & 8220 & 2110 & 6560 & 22890 \\
\hline
\end{tabular}




\begin{tabular}{|c|c|c|c|c|c|c|}
\hline & 秋季 & 11900 & 8900 & 4210 & 5270 & 30280 \\
\hline \multirow{2}{*}{ 全海域 } & 夏季 & 49830 & 28540 & 18240 & 33720 & 130330 \\
\cline { 2 - 7 } & 秋季 & 71970 & 38440 & 30280 & 47310 & 188000 \\
\hline
\end{tabular}

由以上表可以看出, 我国海水水质具体 分布, 可以根据图表数据指导对沿海、河口 的生态环境的风险进行识别和重新定位。

(1)充分利用现有法律法规和环境风险评 价技术导则, 识别沿海、河口区域环境风险。

(2)通过对沿海、河口等区域已识别的源强 进行分析，采用定性分析法、定量分析法对 沿海、河口和近海的旅游休闲娱乐区、工业 园区、城镇生活区进行功能定位。

(3)加强环境后果分析、风险表征分析, 重 新确定沿海工业区环境风险和等级划分。

综合以上分析, 为更好地管控近海水质 问题, 支持可持续发展, 根据河口海岸地貌、 水沙及盐度梯度、化学物质浓度、生物种类 及分布以及人类活动范围和强度等特性、差 异, 建议提出将沿海、河口划分成三个带 （区）。（1）严格保护区;（2）限制开发区; (3) 优化利用区。禁止在保护范围内新建 污染类工矿类企业, 鼓励新动能转换, 鼓励 开展滩涂恢复、湿地修复等治理修复工作。 严格控制改变海岸自然形态和影响海岸生 态环境的开发利用活动, 限制高污染企业产 能扩张, 鼓励环境友好型工矿企业发展。优 先发展海岸带公共服务设施等工程, 恢复海 岸带景观和生态服务功能。

\section{IV. 结论}

截止 2017 年, 国家海洋局组织各级海 洋部门对我国管辖海域重点开展了海水质 量、沉淀物质量和生物多样性状况监测, 共 布设监测站月 13000 个, 获取监测数据 200 余万个。

近几年, 全国各工业园区推行智慧园区, 设置大量的环境监测点, 基本完成园区信息 化、网格化和远程数据输送。

基于上述工作的开展和普及, 对于我国 沿海、河口和近海生态环境治理, 建议海洋 生态环境风险管理如下:

（1）整合国家海洋局和沿海省市信息资 源, 实现对沿海自然资源、生态环境和工业 开发利用活动等的一体化检测、动态化评估 预警和分级分类管控, 以规范沿海带开发秩
序, 识别海岸带资源环境超载的关键要素, 合理控制沿海海域、河口及近海空间开发强 度，推进沿海带综合治理现代化能力。

（2）借鉴发达国家的管理经验，编制国 家级沿海、河口及近海生态环境综合治理总 体规划，坚持陆海统筹、河海一体化的综 合管理体系。

（3）将海岸带、河口带综合治理纳入地 方政府管理体系，建立健全由沿海各级政府 牵头的生态环境综合治理机制, 建立倒逼机 制，强化企业主体责任和政府监督责任。

\section{参考文献}

[1] 2017 年中国海洋生态状况公报。中国国家海洋局官网 [2] 刘岩,全力治理近海海洋生态环境 第001 版中国海洋报 $2013 / 11 / 19$ 